\title{
Ferritin Is a Marker of Inflammation rather than Iron Deficiency in Overweight and Obese People
}

\author{
Abidullah Khan, Wazir Muhammad Khan, Maimoona Ayub, \\ Mohammad Humayun, and Mohammad Haroon
}

\author{
KTH, Peshawar, Pakistan \\ Correspondence should be addressed to Abidullah Khan; dr.abidk@yahoo.com
}

Received 5 August 2016; Accepted 7 December 2016

Academic Editor: Philippe Gual

Copyright (c) 2016 Abidullah Khan et al. This is an open access article distributed under the Creative Commons Attribution License, which permits unrestricted use, distribution, and reproduction in any medium, provided the original work is properly cited.

\begin{abstract}
Background. In clinical practice, serum ferritin is used as a screening tool to detect iron deficiency. However, its reliability in obesity has been questioned. Objectives. To investigate the role of ferritin in overweight and obese people, either as a marker of inflammation or iron deficiency. Methods. On the basis of body mass index (BMI), 150 participants were divided into three equal groups: A: BMI $18.5-25 \mathrm{~kg} / \mathrm{m}^{2}, \mathrm{~B}: \mathrm{BMI} 25-30 \mathrm{~kg} / \mathrm{m}^{2}$, and C: BMI $>30 \mathrm{~kg} / \mathrm{m}^{2}$. Serum iron, total iron binding capacity (TIBC), transferrin saturation, ferritin, C-reactive protein, and hemoglobin $(\mathrm{Hb})$ were measured for each participant and analyzed through SPSS version 16 . Oneway ANOVA and Pearson's correlation tests were applied. Results. Ferritin was the highest in group C $(\mathrm{M}=163.48 \pm 2.23, P<$ $0.001)$ and the lowest in group $\mathrm{A},(\mathrm{M}=152.78 \pm 1.81, P<0.001)$. Contrarily to ferritin, transferrin was the lowest in group $\mathrm{C}$, $(\mathrm{M}=30.65 \pm 1.39, P<0.001)$ and the highest in group $\mathrm{A},(\mathrm{M}=38.66 \pm 2.14, P<0.001)$. Ferritin had a strong positive correlation with both BMI $(r=0.86, P<0.001)$ and CRP $(r=0.87, P<0.001)$ and strong negative correlation with Hb, iron, TIBC, and transferrin saturation $(P<0.001)$. Conclusion. Ferritin is a marker of inflammation rather than iron status in overweight and obese people. Complete iron profile including transferrin, rather than serum ferritin alone, can truly predict iron deficiency in such people.
\end{abstract}

\section{Introduction}

Obesity is a global health problem. In 2014, 600 million adults and 42 million children, less than five years of age, were obese [1]. This is more common in women and is being considered as the most serious threat to human health by different authorities [2]. The normal body mass index (BMI) is $18-25 \mathrm{~kg} / \mathrm{m}^{2}$. Anyone with a BMI of $25-30 \mathrm{~kg} / \mathrm{m}^{2}$ is called overweight, while the term "obesity" is used, when BMI exceeds $30 \mathrm{~kg} / \mathrm{m}^{2}$. This most serious health problem was classified by the American Medical Association (AMA), as a "disease" in 2013 [3].

Overweight and obese people are at risk of developing certain serious complications like obstructive sleep apnea, cor pulmonale, ischemic heart disease, diabetes, and many others [4]. At the same time, it increases the likelihood of iron deficiency (ID) and iron deficiency anemia (IDA), leading to an escalating disease burden [5-9].
Obesity predisposes affected individuals to subclinical inflammation. Many studies have concluded that overweight and obese people are in a state of an ongoing subclinical inflammation that can secondarily lead to more catastrophic events like iron deficiency, malignancy, and so forth [10-13].

Ferritin is used a marker of iron deficiency in various healthcare facilities across the globe [14]. Being an acute phase reactant, serum ferritin level is prone to be higher in overweight and obese people, because of a state of subclinical, but generalized inflammation in them [15-17]. Due to this fact, using serum ferritin as a marker of ID or IDA in overweight or obese people is controversial [16, 17].

Obesity is an emerging health related concern in Pakistan and so are ID and IDA [18-20]. It is also worth mentioning that serum ferritin assay is the most commonly used blood test to diagnose ID or IDA, not only in Pakistan, but in other developing countries of the world also. This is so because there is a relative scarcity of more specific test for 


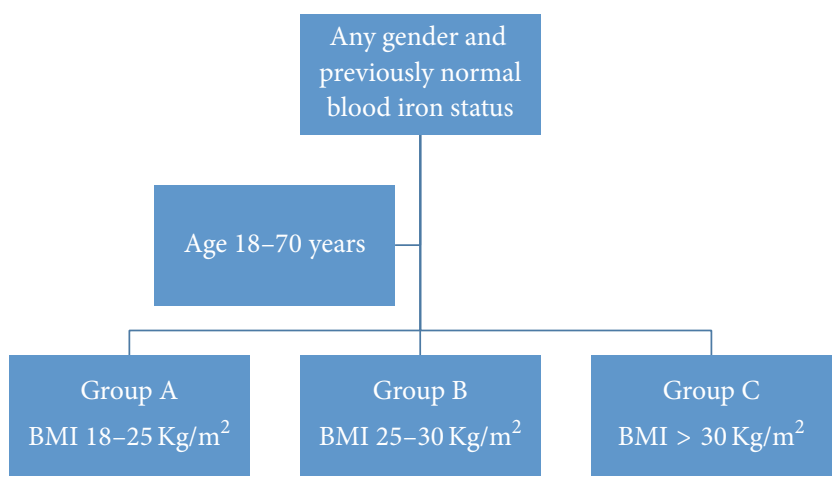

FIGURE 1: Inclusion criteria for suitability in the study sample.

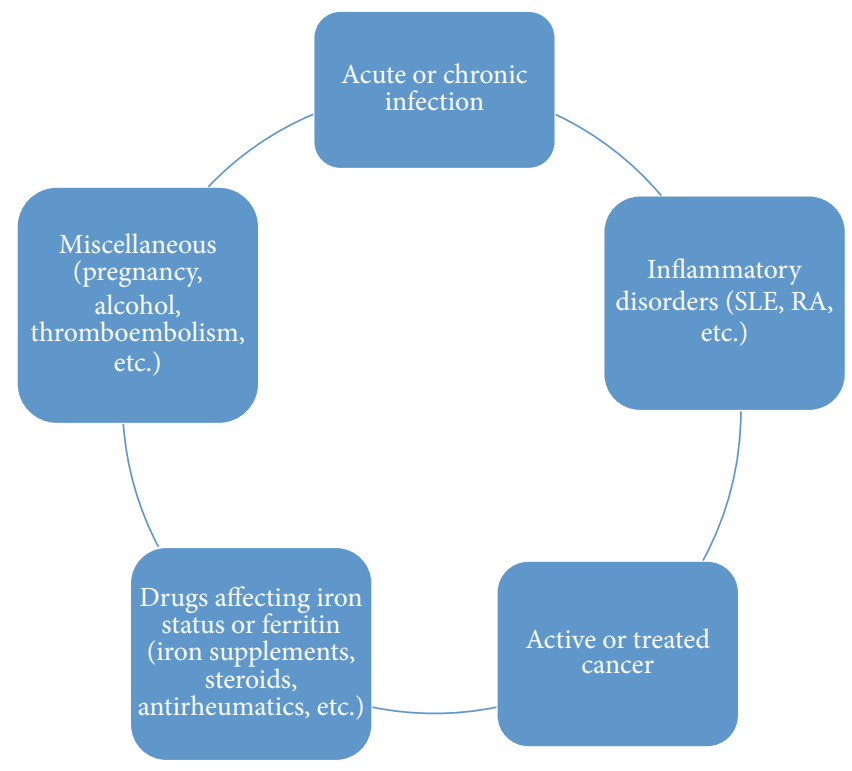

Figure 2: An overview of the chief exclusion criteria.

the diagnosis of ID or IDA like transferrin saturation or total iron binding capacity (TIBC) and so forth. Therefore, the use and interpretation of serum ferritin assay alone become challenging, because serum ferritin may not be a true measure of an underlying iron deficiency in overweight and obese people. Therefore, this study will focus on correlating serum ferritin with C-reactive protein (CRP) and its association with iron and BMI, and to find out whether, it is safe to keep using serum ferritin as a true measure of iron deficiency in overweight and obese people or not.

\section{Material and Methods}

This cross-sectional, observational study was conducted in the department of medicine of Khyber Teaching Hospital (KTH), Peshawar, Pakistan, between September 2015 and July 2016. This study was approved by the hospital's ethics review committee and included 150 otherwise healthy participants. Informed written consent was obtained from every participant individually.
A structured questionnaire including closed ended questions regarding demographic details, present and past med$\mathrm{ical} /$ surgical history, any history of recent infections, recent or previous drug history, especially, iron tablets or injections, steroids or oral contraceptive pills, and chemotherapeutic medications like methotrexate, azathioprine, and so forth was used.

An overview of the inclusion and exclusion criteria is given below (Figures 1 and 2). The study included patients from both the genders in the age range of 18 to 70 years. Patients already diagnosed with iron deficiency or iron deficiency anemia were excluded from the study. Similarly, those diagnosed with iron overload were also excluded. Other exclusion criteria were set on the basis of medical conditions which could potentially affect the body iron stores or ferritin, such as pregnancy, alcoholism, hemoglobinopathies, diabetes mellitus, bleeding disorders, any acute or chronic inflammatory conditions like rheumatoid arthritis (RA) or systemic lupus erythematosus (SLE), and any acute illnesses during the preceding one month or chronic infections like 
TABLE 1: Descriptive statistics of different study variables in each group.

\begin{tabular}{|c|c|c|c|c|c|c|}
\hline \multirow{2}{*}{ Variable } & \multicolumn{2}{|c|}{ Group A $(N=50)$} & \multicolumn{2}{|c|}{ Group B $(N=50)$} & \multicolumn{2}{|c|}{ Group C $(N=50)$} \\
\hline & Mean & SD & Mean & $\mathrm{SD}$ & Mean & $\mathrm{SD}$ \\
\hline Age (years) & 44.84 & 6.16 & 44.84 & 6.17 & 44.44 & 7.17 \\
\hline $\operatorname{BMI}\left(\mathrm{kg} / \mathrm{m}^{2}\right)$ & 22.36 & 1.08 & 27.18 & 0.80 & 31.18 & 0.85 \\
\hline $\mathrm{Hb}(\mathrm{gm} / \mathrm{dL})$ & 14.13 & 0.83 & 12.68 & 0.68 & 11.86 & 0.88 \\
\hline Iron $(\mu \mathrm{mol} / \mathrm{L})$ & 24.86 & 1.24 & 21.36 & 1.04 & 17.68 & 1.18 \\
\hline TIBC $(\mu \mathrm{mol} / \mathrm{L})$ & 63.56 & 0.50 & 59.52 & 0.86 & 57.44 & 1.59 \\
\hline TSAT (\%) & 38.66 & 2.14 & 35.36 & 1.63 & 30.65 & 1.39 \\
\hline Ferritin $(\mu \mathrm{g} / \mathrm{L})$ & 152.78 & 1.81 & 158.32 & 1.99 & 163.48 & 2.23 \\
\hline $\mathrm{CRP}(\mathrm{mg} / \mathrm{L})$ & 5.28 & 0.73 & 7.58 & 1.01 & 11.46 & 1.46 \\
\hline
\end{tabular}

Group A: BMI $18.5-25 \mathrm{~kg} / \mathrm{m}^{2}$, group B: BMI $25-30 \mathrm{~kg} / \mathrm{m}^{2}$, and group C: BMI > $30 \mathrm{~kg} / \mathrm{m}^{2}$, Hb: hemoglobin, TIBC: total iron binding capacity, TSAT: transferrin saturation, CRP: C-reactive protein, and BMI: body mass index.

tuberculosis, brucellosis, and so forth. Patients on drugs which could influence serum iron or ferritin like any use of iron supplements, steroids, oral contraceptive pills (OCPs), nonsteroidal anti-inflammatory drugs (NSAIDS), disease modifying antirheumatic drugs like methotrexate, azathioprine, hydroxychloroquine, and so forth and those with cancer or on active treatment for it were also excluded from the study.

The final 150 individuals included in the study were divided into three groups, each group consisting of 50 participants as follows: group A: BMI $18.5-25 \mathrm{~kg} / \mathrm{m}^{2}$, group B: BMI $25-30 \mathrm{~kg} / \mathrm{m}^{2}$, and group C: BMI $>30 \mathrm{~kg} / \mathrm{m}^{2}$.

The BMI was calculated using the formula weight $(\mathrm{kg}) /$ height $\left(\mathrm{meter}^{2}\right)$. A weight scale with a built-in stadiometer was used to measure the weight and height of all the subjects in kilograms and meters, respectively. A morning sample of $5 \mathrm{~mL}$ of venous blood was drawn; $3 \mathrm{~mL}$ was put in gel tubes for the determination of serum ferritin, iron, total iron binding capacity (TIBC), transferring saturation, and C-reactive protein (CRP), while $2 \mathrm{~mL}$ was put in an EDTA tube for hemoglobin $(\mathrm{Hb})$ determination. Serum ferritin and CRP were measured by using enzyme linked immunosorbent assay (ELISA) method, serum iron was measured using enzymatic colorimetric method, and $\mathrm{Hb}$ was measured on automated analyzer Sysmex. Transferrin saturation was determined by using the formula; iron/TIBC $\times 100$. All these tests were done by the same technician in the main laboratory of Khyber Teaching Hospital (KTH), Peshawar.

All the data was entered into and analyzed by SPSS version 16. In order to compare the means of different study variables, one-way ANOVA with Turkey-HSD was used. Pearson's correlation test was run to analyze an association of BMI with serum ferritin, CRP, serum iron, TIBC, and transferrin saturation. $P$ value of $<0.05$ was considered as significant.

\section{Results}

Amongst all the participants, $47.3 \%$ were males and 52.7\% were females. The mean age, body mass index (BMI), and serum ferritin $(\mu \mathrm{g} / \mathrm{L})$ of all the participants were $44.71 \pm 6.48$,
$26.91 \pm 3.73$, and $158.19 \pm 4.82$, respectively. Group specific descriptive statistics are given below (Table 1).

The data was tested for the assumptions of homogeneity of variances and normality. One-way ANOVA was used to compare the means of different dependent variables between the three groups, namely, group A, group B, and group $\mathrm{C}$, to find out any impact of obesity on the dependent variables, namely, ferritin, Iron, TIBC, hemoglobin ( $\mathrm{Hb})$, and transferrin saturation. Ferritin was the highest in group $\mathrm{C}$ $(\mathrm{M}=163.46, \mathrm{SD}=2.23, P<0.001)$, higher in group $\mathrm{B}$ $(\mathrm{M}=158.32, \mathrm{SD}=1.99, P<0.001)$, and lowest in group A $(\mathrm{M}=152-78, \mathrm{SD}=1.81, P<0.001)$. However, despite the highest ferritin level in group $\mathrm{C}$ (the obesity group), transferrin saturation was the lowest $(\mathrm{M}=30.65, \mathrm{SD}=1.39$, $P<0.001)$. Similarly, along with transferrin, both $\mathrm{Hb}$ and iron were the highest in group $\mathrm{A}$, intermediate in group $\mathrm{B}$, and the lowest in group C (Table 1). The post hoc analysis for these variables was significant at $P<0.001$ in each group (Table 2). There was a statistically significant difference between the three groups for ferritin $(F(2,147)=350.80, P<0.001)$, hemoglobin $(F(2,147)=101.90, P<0.001)$, and iron $(F(2,147)=644.54, P<0.001)$, respectively. The estimate of effect size (Partial Eta Squared) for the difference of ferritin, iron, and $\mathrm{Hb}$ between the three groups was $0.83,0.86$, and 0.58 , respectively.

For both CRP and transferrin saturation (TSAT), the assumption of homogeneity of variances was not tenable $(P<0.05)$. However, robust tests for the equality of means were statistically significant $(P<0.01$ for both Welch and Brown-Forsythe tests). Moreover, one-way ANOVA showed a statistically significant difference between the three groups with regard to CRP and TSAT. The results of one-way ANOVA for CRP and TSAT were $F(2,147)=396.87, P<$ 0.001 and $F(2,147)=262.87, P<0.001$, respectively. CRP was found to be highest in group $\mathrm{C}(\mathrm{M}=11.46, S D=1.46$, $P<0.001)$, higher in group $\mathrm{B}(\mathrm{M}=7.58, S D=1.01$, $P<0.001)$, and the lowest in group $\mathrm{A}(\mathrm{M}=5.28, \mathrm{SD}=0.73$, $P<0.001)$.

Finally a correlation test was run between the BMI and the dependent variables, namely, ferritin, iron, transferrin, TIBC, and CRP (Table 3). It is worth mentioning that both ferritin and CRP correlated positively with BMI $(r=0.86$, 


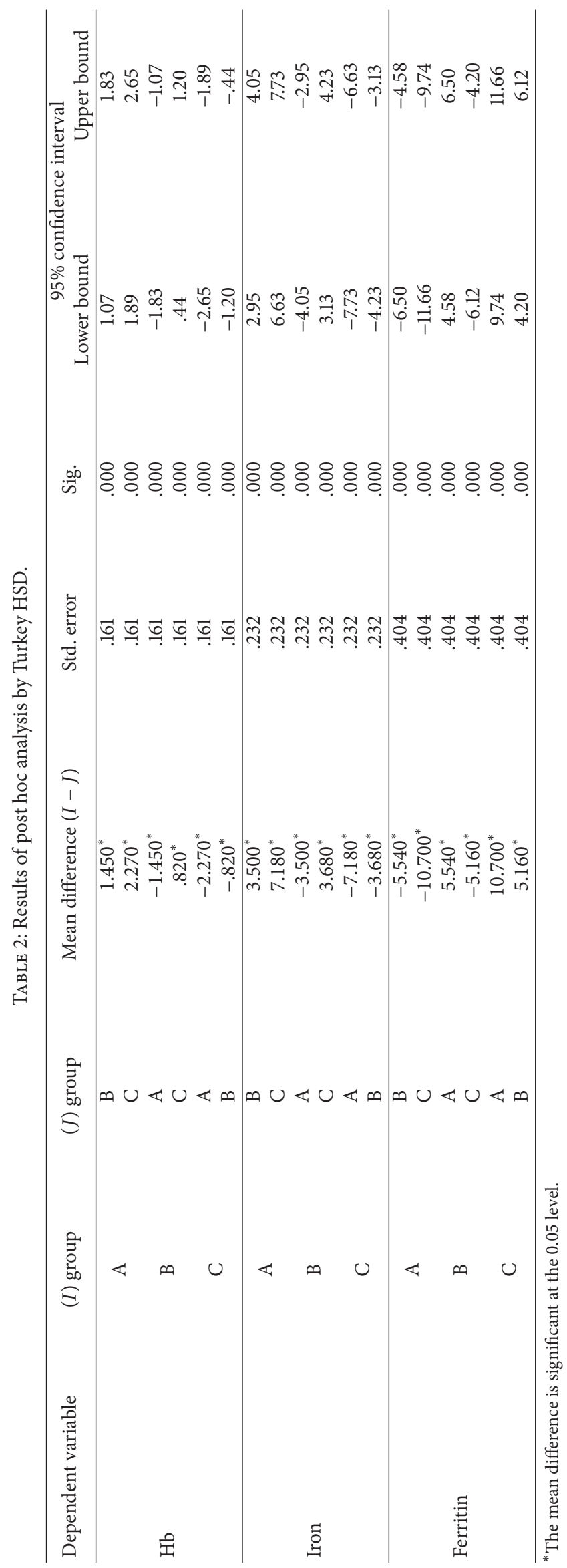


TABLE 3: Pearson's correlation of BMI with test variables (note a strong positive correlation with ferritin and CRP).

\begin{tabular}{lcr}
\hline Variable & Pearson's value $(r)$ & $P$ value \\
\hline HB & -0.77 & $<0.001$ \\
Iron & -0.89 & $<0.001$ \\
TIBC & -0.87 & $<0.001$ \\
Transferrin & -0.84 & $<0.001$ \\
Ferritin & 0.86 & $<0.001$ \\
CRP & 0.89 & $<0.001$ \\
\hline
\end{tabular}

TABLE 4: Pearson's correlation of ferritin with the test variables (note a strong positive correlation with CRP/BMI and an inverse correlation with transferrin).

\begin{tabular}{lcr}
\hline Variable & Pearson's value $(r)$ & $P$ value \\
\hline Hb & -0.62 & $<0.001$ \\
Iron & -0.89 & $<0.001$ \\
TIBC & -0.84 & $<0.001$ \\
TSAT & -0.86 & $<0.001$ \\
CRP & 0.87 & $<0.001$ \\
BMI & 0.86 & $<0.001$ \\
\hline
\end{tabular}

$P<0.001$ and $r=0.89, P<0.001$, resp.). However, there was a strong negative correlation between the BMI and the rest of the three variables, namely, iron $(r=-0.89, P<0.001)$, TIBC $(r=-0.87, P<0.001)$, and TSAT $(R=-0.84$, $P<0.001)$. It is also notable that ferritin had a strong positive correlation with CRP $(r=0.87, P<0.01)$ but a negative one with iron $(r=-0.89, P<0.001)$, TIBC $(r=-0.85$, $P<0.001)$, and transferrin saturation $(r=-0.86, P<0.001)$. The detailed breakdown is given (Table 4$)$. It must be noted that, for the falling values of iron, TIBC, and TSAT, as one moves upwards from group A to group C, there was a not only a corresponding decline in the level of hemoglobin $(\mathrm{Hb})$, but also a significant increase in the level of ferritin $(P<0.001)$.

\section{Discussion}

Iron deficiency (ID) with or without anemia is common in obese people and has certain mechanisms involved in its pathogenesis mainly a state of subclinical inflammation. The low iron levels in overweight and obese subjects are most probably caused by the inflammatory mechanisms, which arrest iron in the reticuloendothelial system by releasing different inflammatory mediators like cytokines and so forth $[21,22]$. Our study showed a positive correlation between ferritin and CRP, signifying an underlying low grade inflammation, leading to subsequent iron deficiency, most probably, because of inflammation mediated iron sequestration in the reticuloendothelial system.

Ferritin is an acute phase reactant and is potentially higher in any infective or inflammatory process, making its careful interpretation necessary in such situations. In a recent study, high levels of ferritin were positively correlated with the risk of metabolic syndrome and obesity [23]. In another study, ferritin was found to be positively associated with CRP [24]. Our findings are consistent with these results. However, in sharp contrast to our statistics, a study by Eftekhari et al. concluded that serum ferritin was lower in obese people [25].

Obesity is one of the biggest health challenges of the 21st century. Association of ID/IDA with obesity doubles the ill health effects of the obesity itself. Though chronic inflammation caused by excess adipose tissue, rather than dietary factors, offers a plausible explanation for ID or IDA in obese people, looking for the existence of both acute and chronic infections, and inflammatory conditions need to be considered as well. Moreover, treating IDA in obese people is another challenge itself, as they tend to respond poorly to iron supplementation $[5,26]$. In another recent study, administering both oral iron and ascorbic acid as an enhancer of its absorption from the gut made little difference in correcting ID or IDA in overweight or obese individuals [27].

IDA is most commonly caused by nutritional deficiency. On the other hand, obesity is often caused by overnutrition. Hence, the coexistence of both IDA and obesity in the same person represents the opposite ends of the spectrum of under and overnutrition. However, amongst the different factors responsible for their mutual coexistence like dilutional hypoferremia, poor dietary iron intake, increased iron demands, and/or impaired iron absorption, a chemical called hepcidin was recently found to be the main culprit for ID or IDA in obesity. Hepcidin was found in higher titers in obese and overweight individuals. Hepcidin works by causing subclinical inflammation, decreases iron absorption from the gut, and blunts the effects of iron fortification [28, 29]. Reducing weight may lower hepcidin, which may in return improve the iron stores of the body. Treating obesity through surgical approaches like Roux-en-Y gastric bypass (RYGB) is unfortunately related to iron deficiency also. In a recent Chinese study, iron deficiency and IDA both were found to be extremely frequent after RYGB in obese patients with T2DM at 2-year follow-up [30]. It is therefore recommended 
to screen overweight and obese people for iron deficiency, both before and after any antiobesity surgical intervention is undertaken.

It is to be stated that the results of our study were according to the expectations of the authors. As is evident from our results, ferritin was not a true indicator of an underlying iron deficiency in our study population of overweight and obese individuals. Rather, ferritin correlated positively with the inflammatory marker, $\mathrm{CRP}$, and $\mathrm{BMI}$, making ferritin a marker of inflammation rather than iron status in overweight and obese people. However, we recommend further studies and would advocate a bigger sample size, in order to arrive at a more logical conclusion.

\section{Conclusion}

Ferritin is a marker of inflammation rather than iron status in overweight and obese individuals. Being an acute phase reactant, a high ferritin level secondary to subclinical inflammation in overweight and obese people may mask an underlying iron deficiency. It is therefore recommended to request a complete iron studies profile including transferrin saturation, ferritin, total iron binding capacity (TIBC), and serum iron, to confidently exclude ID in obese or overweight subjects.

\section{Abbreviations}

ID: Iron deficiency

IDA: Iron deficiency anemia

CRP: C-reactive protein

BMI: Body mass index

TSAT: Transferrin saturation

TIBC: Total iron binding capacity

Hb: Hemoglobin

RYGB: Roux-en-Y gastric bypass.

\section{Competing Interests}

The authors declare that there is no conflict of interests regarding the publication of this paper.

\section{Authors' Contributions}

Abidullah Khan, Mohammad Humayun, and Maimoona Ayub conceived the idea. All the authors contributed to the drafting, revising, and proofreading of this manuscript. All the authors approved the final manuscript.

\section{References}

[1] WHO, Obesity and Overweight Fact Sheet N 311, WHO, Geneva, Switzerland, 2015.

[2] J. K. Dibaise and A. E. Foxx-Orenstein, "Role of the gastroenterologist in managing obesity," Expert Review of Gastroenterology and Hepatology, vol. 7, no. 5, pp. 439-451, 2013.

[3] https://en.wikipedia.org/wiki/Obesity.

[4] D. W. Haslam and W. P. James, "Obesity," The Lancet, vol. 366, no. 9492, pp. 1197-1209, 2005.
[5] C. Hutchinson, "A review of iron studies in overweight and obese children and adolescents: a double burden in the young?" European Journal of Nutrition, vol. 55, no. 7, pp. 2179-2197, 2016.

[6] A. C. Cepeda-Lopez, A. Melse-Boonstra, M. B. Zimmermann, and I. Herter-Aeberli, "In overweight and obese women, dietary iron absorption is reduced and the enhancement of iron absorption by ascorbic acid is one-half that in normal-weight women," The American Journal of Clinical Nutrition, vol. 102, no. 6, pp. 1389-1397, 2015.

[7] J. Baumgartner, C. M. Smuts, I. Aeberli, L. Malan, H. Tjalsma, and M. B. Zimmermann, "Overweight impairs efficacy of iron supplementation in iron-deficient South African children: a randomized controlled intervention," International Journal of Obesity, vol. 37, no. 1, pp. 24-30, 2013.

[8] L. Zhao, X. Zhang, Y. Shen, X. Fang, Y. Wang, and F. Wang, "Obesity and iron deficiency: a quantitative meta-analysis," Obesity Reviews, vol. 16, no. 12, pp. 1081-1093, 2015.

[9] H. L. Cheng, C. Bryant, R. Cook, H. O’Connor, K. Rooney, and K. Steinbeck, "The relationship between obesity and hypoferraemia in adults: a systematic review," Obesity Reviews, vol. 13, no. 2, pp. 150-161, 2012.

[10] A. Vehapoglu, S. Turkmen, N. Goknar, and Ö. F. Özer, "Reduced antioxidant capacity and increased subclinical inflammation markers in prepubescent obese children and their relationship with nutritional markers and metabolic parameters," Redox Report, vol. 21, no. 6, pp. 271-280, 2016.

[11] D. Herrera-Covarrubias, G. A. Coria-Avila, C. FernándezPomares, G. E. Aranda-Abreu, J. Manzo Denes, and M. E. Hernández, "Obesity as a risk factor in the development of cancer," Revista Peruana de Medicina Experimental y Salud Pública, vol. 32, no. 4, pp. 766-776, 2015.

[12] A. Kohlgruber and L. Lynch, "Adipose tissue inflammation in the pathogenesis of type 2 diabetes," Current Diabetes Reports, vol. 15, no. 11, article 92, 2015.

[13] J.-P. Bastard, M. Maachi, C. Lagathu et al., "Recent advances in the relationship between obesity, inflammation, and insulin resistance," European Cytokine Network, vol. 17, no. 1, pp. 4-12, 2006.

[14] P. Gupta Bansal, G. Singh Toteja, N. Bhatia et al., "Deficiencies of serum ferritin and vitamin B12, but not folate, are common in adolescent girls residing in a slum in Delhi," International Journal for Vitamin and Nutrition Research, vol. 85, no. 1-2, pp. 14-22, 2015.

[15] H. T. O’Brien, R. Blanchet, D. Gagné, J. Lauzière, and C. Vézina, "Using soluble transferrin receptor and taking inflammation into account when defining serum ferritin cutoffs improved the diagnosis of iron deficiency in a group of Canadian preschool Inuit children from Nunavik," Anemia, vol. 2016, Article ID 6430214, 10 pages, 2016.

[16] J.-W. Kim, D. H. Kim, Y. K. Roh et al., "Serum ferritin levels are positively associated with metabolically obese normal weight: a nationwide population-based study," Medicine, vol. 94, no. 52, Article ID e2335, 2015.

[17] Y.-F. Huang, T.-S. Tok, C.-L. Lu, H.-C. Ko, M.-Y. Chen, and S. C. Chen, "Relationship between being overweight and iron deficiency in adolescents," Pediatrics \& Neonatology, vol. 56, no. 6, pp. 386-392, 2015.

[18] S. A. Patel, M. K. Ali, D. Alam et al., "Obesity and its relation with diabetes and hypertension: a cross-sectional study across 4 geographical regions," Global Heart, vol. 11, no. 1, pp. 71.e479.e4, 2016. 
[19] M. Khaskheli, S. Baloch, A. S. Baloch, S. Baloch, and F. K. Khaskheli, "Iron deficiency anaemia is still a major killer of pregnant women," Pakistan Journal of Medical Sciences, vol. 32, no. 3, pp. 630-634, 2016.

[20] M. A. Habib, K. Black, S. B. Soofi et al., "Prevalence and predictors of iron deficiency anemia in children under five years of age in Pakistan, a secondary analysis of national nutrition survey data 2011-2012," PLOS ONE, vol. 11, no. 5, Article ID 0155051, 2016.

[21] A. Lecube, C. Hernández, D. Pelegrí, and R. Simó, "Factors accounting for high ferritin levels in obesity," International Journal of Obesity, vol. 32, no. 11, pp. 1665-1669, 2008.

[22] S.-B. Chen, Y.-C. Lee, K.-H. Ser et al., "Serum C-reactive protein and white blood cell count in morbidly obese surgical patients," Obesity Surgery, vol. 19, no. 4, pp. 461-466, 2009.

[23] R. F. Gillum, "Association of serum ferritin and indices of body fat distribution and obesity in mexican american menthe third national health and nutrition examination survey," International Journal of Obesity, vol. 25, no. 5, pp. 639-645, 2001.

[24] F. Alam, F. Fatima, S. Orakzai, N. T. Iqbal, and S. S. Fatima, "Elevated levels of ferritin and hs-CRP in type 2 diabetes," Journal of the Pakistan Medical Association, vol. 64, no. 12, pp. 1389-1391, 2014.

[25] M. H. Eftekhari, H. Mozaffari-Khosravi, and F. Shidfar, “The relationship between BMI and iron status in iron-deficient adolescent Iranian girls," Public Health Nutrition, vol. 12, no. 12, pp. 2377-2381, 2009.

[26] C. Jericó, I. Bretón, A. García Ruiz de Gordejuela et al., "Diagnosis and treatment of iron deficiency, with or without anemia, before and after bariatric surgery," Endocrinologia $y$ Nutricion, vol. 63, no. 1, pp. 32-42, 2016.

[27] A. C. Cepeda-Lopez, A. Melse-Boonstra, M. B. Zimmermann, and I. Herter-Aeberli, "In overweight and obese women, dietary iron absorption is reduced and the enhancement of iron absorption by ascorbic acid is one-half that in normal-weight women," American Journal of Clinical Nutrition, vol. 102, no. 6, pp. 1389-1397, 2015.

[28] A. C. Cepeda-Lopez, I. Aeberli, and M. B. Zimmermann, "Does obesity increase risk for iron deficiency? a review of the literature and the potential mechanisms," International Journal for Vitamin and Nutrition Research, vol. 80, no. 45, pp. 263-270, 2010.

[29] H. P. Villarroel, O. M. Arredondo, and G. M. Olivares, "Hepcidin as a central mediator of anemia of chronic diseases associated with obesity," Revista Medica de Chile, vol. 141, no. 7, pp. 887-894, 2013.

[30] H. Yu, R. Du, N. Zhang, M. Zhang, Y. Tu, and L. Zhang, "Iron-Deficiency Anemia after Laparoscopic Roux-en-Y gastric bypass in chinese obese patients with type 2 diabetes: a 2-Year Follow-Up Study," Obesity Surgery, vol. 26, no. 11, pp. 2705-2711, 2016. 


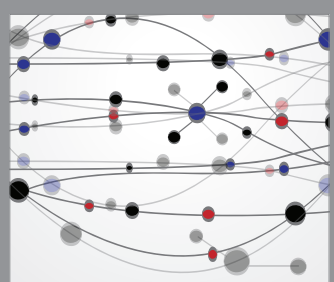

The Scientific World Journal
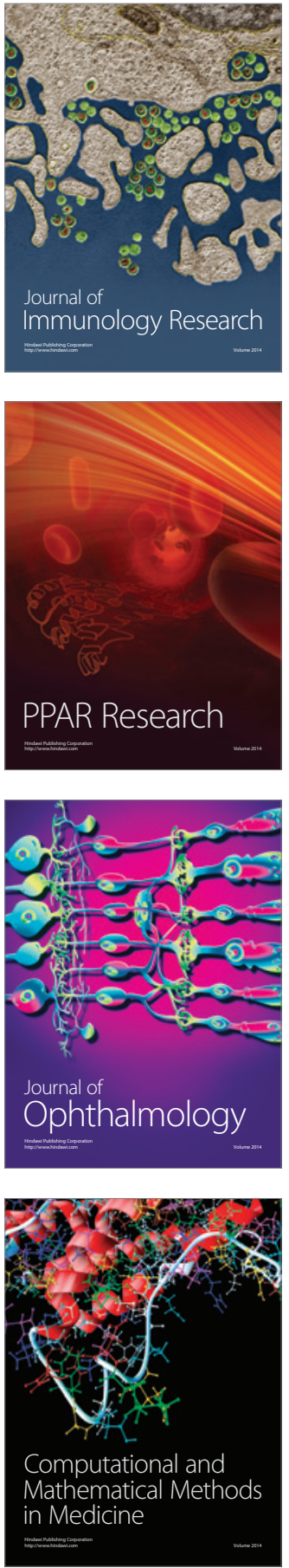

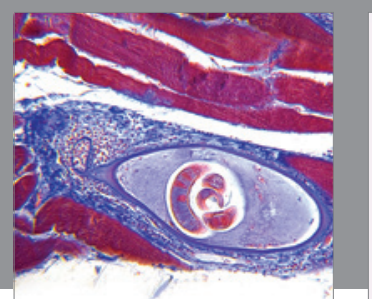

Gastroenterology Research and Practice

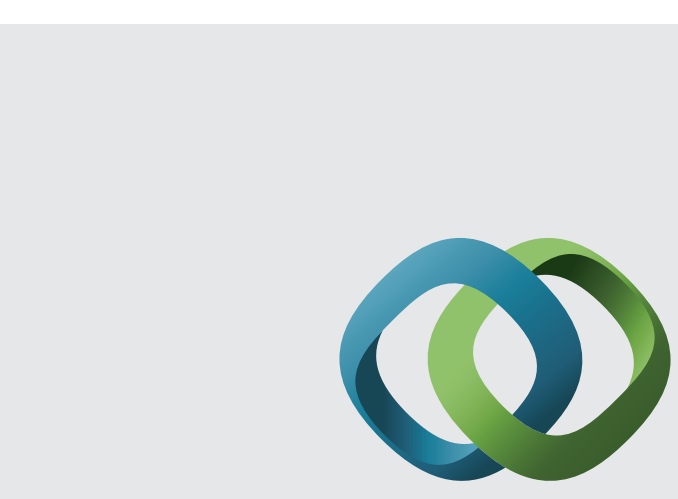

\section{Hindawi}

Submit your manuscripts at

http://www.hindawi.com
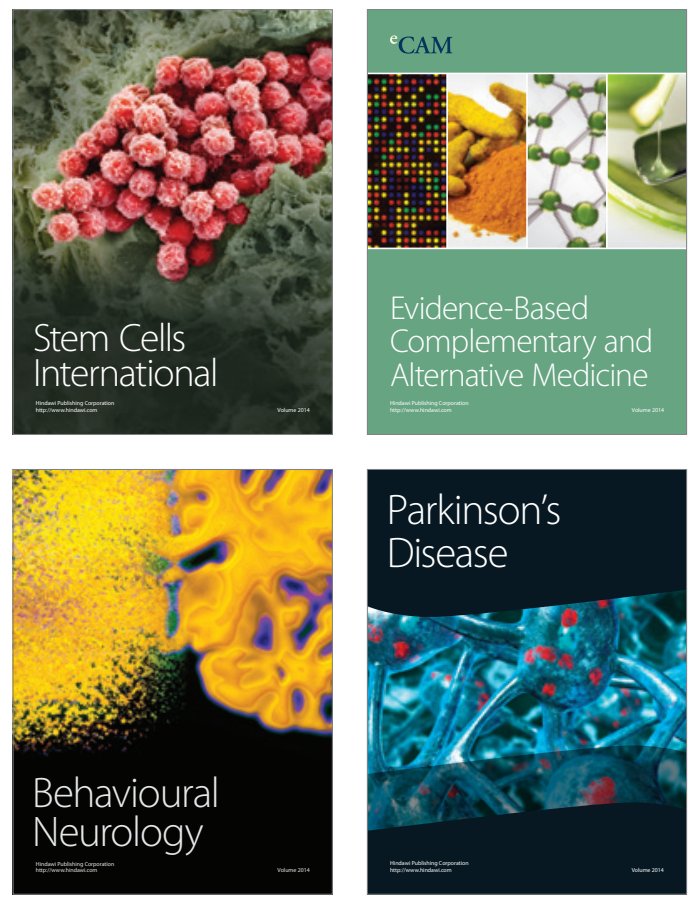
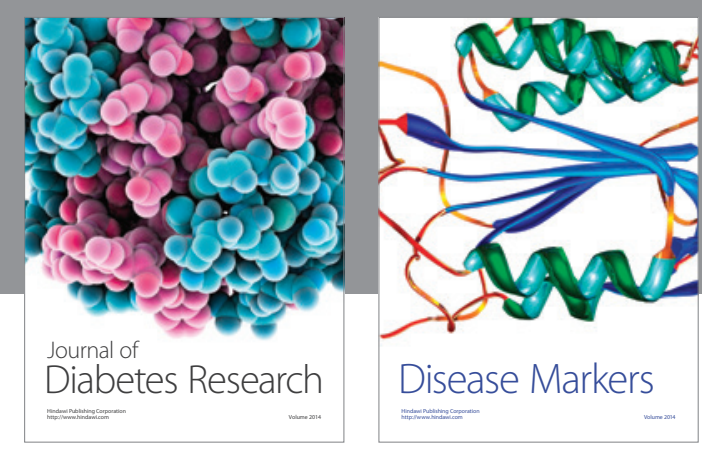

Disease Markers
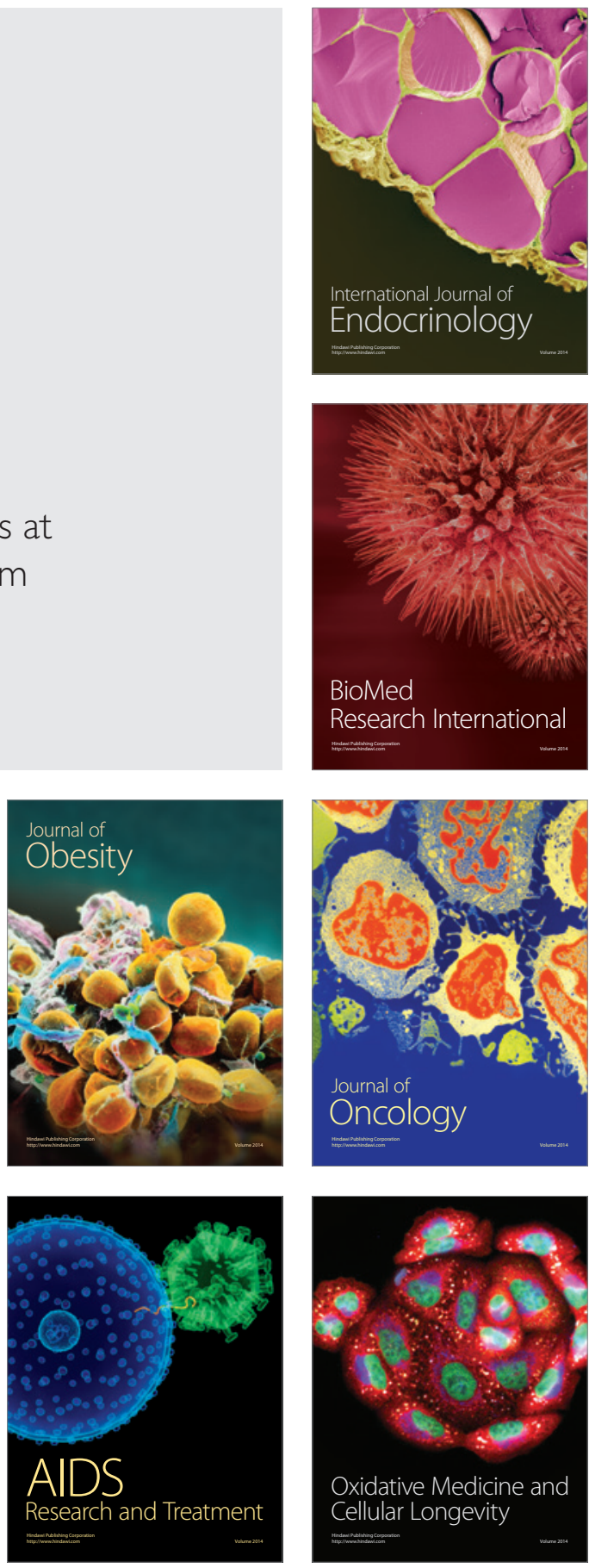